\title{
Correlation of histopathological features of pannus with patterns of damage in different joints in rheumatoid arthritis*
}

\author{
S A Allard, K D Muirden, R N Maini
}

The Kennedy Institute of Rheumatology, London S A Allard

R N Maini

Department of Medicine, University of Melbourne, Australia

K D Muirden

Correspondence to:

Professor R N Maini,

The Kennedy Institute of

Rheumatology,

London W6 7DW.

Accepted for publication 16 May 1990

${ }^{*}$ Part of the work included in this paper was presented at the British Society for Rheumatology meeting November 1987

(Br J Rheromatol 1987; 26

(suppl 2): 29)

\begin{abstract}
The cartilage-pannus junction has been studied in multiple sections from 23 rheumatoid joints. Changes suggesting a metaplastic reaction of the articular cartilage, termed transitional fibroblastic zone, were commonly found in hips and knees, but were rarely present in metatarsophalangeal joints, in which an invasive pannus with cartilage degradation in close association with inflammatory cells was seen. Thus when multiple sections from rheumatoid joints were examined a transitional fibroblastic zone was found in 1/15 (7\%) sections from metatarsophalangeal joints compared with 29/57 $(51 \%)$ and $15 / 48(31 \%)$ sections from knee and hip joints respectively. In contrast, an invasive pannus occurred in 11/15 (73\%) sections from metatarsophalangeal joints compared with $22 / 57(39 \%)$ sections from knees and 19/48 (40\%) sections from hips. These findings led to the suggestion that this pathological variation between different joints may explain the predominance of erosive change in small joints as compared with joint space narrowing with secondary osteoarthritis found in large joints in rheumatoid arthritis. Inappropriate comparisons between different joints may in part explain the variation in findings of previous histopathological studies.
\end{abstract}

Descriptions of the cartilage-pannus junction in rheumatoid joints have varied considerably. ${ }^{1-10}$ This has resulted in controversy about both the function and origin of pannus in rheumatoid arthritis. ${ }^{11-15}$

Recent immunohistochemical studies have helped to identify the phenotype of cells at the rheumatoid cartilage-pannus junction ${ }^{16-20}$ and

phages, fibroblasts, and endothelial cells seem to be in immediate contact with the hyaline cartilage and represent invasive pannus as classically envisaged.

In this study we reported the prevalence and distribution of these two types of cartilagepannus junction in different joints and sought a relation between the state of degradation of the articular cartilage in relation to the type of junction present. A correlation between these histological patterns and characteristic radiological changes seen in different joints in rheumatoid arthritis is postulated.

\section{Materials and methods}

Samples of tissue were obtained from the synovial-cartilage junction of different joints removed during operation from patients with classical or definite rheumatoid arthritis. One hundred and twenty four multiple sections from 23 joints (11 knees, seven hips, four metatarsophalangeal joints, one radial head) of 20 patients were studied. The samples varied in size, ranging from about $1 \mathrm{~cm}$ to $4 \mathrm{~mm}$ in length along the interface between cartilage and synovium. They were obtained from the medial or lateral surfaces of the femoral condyles of knees, and from available cartilage-synovial junctional areas of femoral and metatarsal heads. In this study each forefoot or set of metatarsophalangeal joints is considered to represent one joint.

Specimens studied had either been fixed in Carnoy's fixative and embedded in paraffin wax or snap frozen in liquid nitrogen and stored at $-70^{\circ} \mathrm{C}$. Sections $(5 \mu \mathrm{m})$ were cut and the frozen sections postfixed in buffered formalin. All sections were stained with haematoxylin and eosin, toluidine blue, and safranin $\mathrm{O}$ to show the presence of proteoglycans. ${ }^{22}$

Each section was assessed without knowledge origin of this tissue. Using monoclonal antibodies, we have shown that this junction in rheumatoid arthritis can be divided into two main histological patterns determined by the presence or absence of a transitional fibroblastic zone. ${ }^{20}$ This zone is found overlying the cartilage surface and results in an indistinct margin between pannus and cartilage. Cells and matrix within this zone stain positively with monoclonal antibodies specific for keratan sulphate and type II collagen. ${ }^{20} 21$ These findings have led us to suggest that the transitional fibroblastic zone arises as a result of phenotypic change in chondrocytes. In contrast, the fibroblastic zone is absent from sections in which a distinct well defined junction is present between pannus and articular cartilage. In this latter situation macroof the anatomical origin of the section by two independent observers for $(a)$ the presence or absence of pannus; $(b)$ the type of cartilagepannus junction present; and $(c)$ the condition of the underlying cartilage.

The cartilage-pannus junction was classified as either 'indistinct', determined by the presence of a transitional fibroblastic zone, or 'distinct', invasive-type pannus (fig 1). The depth of the fibroblastic zone varied in indistinct junctions and was not regarded as present unless greater than three cells in depth. This was to avoid including cells which might have been part of the upper zone (zone 1) of normal articular cartilage.

The condition of the underlying cartilage was 


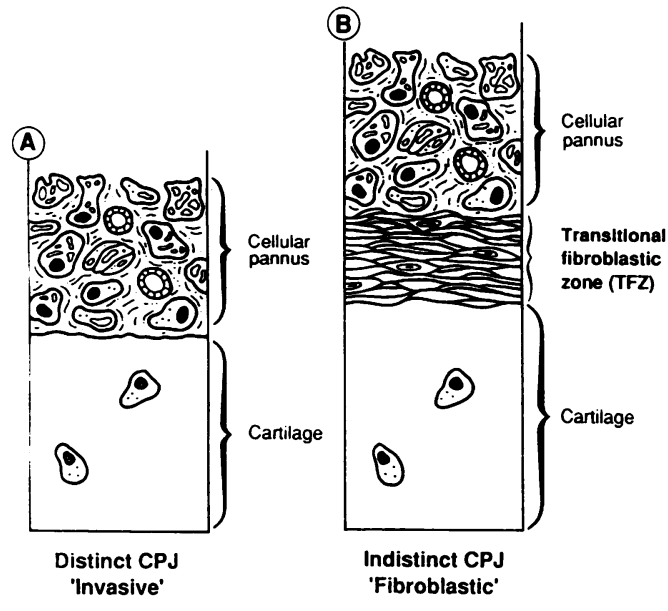

Figure 1 Schematic representation of the two main types of cartilage-pannus junction (CPY) in rheumatoid joints. $(A)$ Invasive pannus, in which a distinct junction is readily identified between cellular pannus lying immediately adjacent to the cartilage surface. (B) Fibroblastic pannus, in which the presence of a transitional fibroblastic zone creates an indistinct junction between cartilage and cellular, vascular pannus.

assessed with particular attention to the degree of proteoglycan depletion, as assessed by staining with toluidine blue and safranin $\mathrm{O}$, and the degree of chondrocyte necrosis, which was defined as cells showing nuclear karyorrhexis or empty lacunae associated with absent pericellular proteoglycans. A semiquantitative scoring system for proteoglycan matrix staining and degree of chondrocyte necrosis was used (table 1). Each section was scored for the degree of proteoglycan depletion ( 0 to 3 ) and chondrocyte necrosis (0 to 3 ). The observers reassessed sections in which their scores differed and agreed on a final score. A score reflecting cartilage degradation (maximum=6) was obtained for cartilage-pannus junctions with a fibroblastic (indistinct) or invasive-type (distinct) pattern.

Table 1 Scoring system for assessment of articular cartilage

Proteoglycan depletion

Score: 0-Normal staining (no depletion)

1-Reduced but substantial staining

2-Small/patchy staining

3-Absent staining for proteoglycan

Chondrocyte necrosis (\% chondrocyte death)

Score: $0-<10$

$1-10-25$

$2-25-75$

$3 \rightarrow 75$

Combined score $6=$ maximum cartilage degradation.

\section{STATISTICAL ANALYSIS}

The prevalence of a transitional fibroblastic zone or invasive cartilage-pannus junction in different joints and within each joint was assessed with the Mann-Whitney $U$ and Wilcoxon matched pairs signed rank tests respectively. The relation between the degree of cartilage degradation and the type of cartilagepannus junction was assessed with the MannWhitney $U$ test and that between proteoglycan depletion and chondrocyte necrosis by Spearman's correlation coefficient.

The reproducibility of the scoring system for evaluating interobserver variation between the two independent 'blinded' observers showed no significant difference between the scorers for either proteoglycan matrix staining $(p>0.05)$ or chondrocyte necrosis $(p>0.05)$ as determined by the Wilcoxon matched pairs signed rank test. There was also good correlation between scorers (Spearman's rank correlation) for both variables (proteoglycan matrix staining, $\mathrm{p}<0.01$; chondrocyte necrosis, $\mathrm{p}<0.007)$.

\section{RADIOLOGICAL ASSESSMENT}

Radiographs of the joints taken before operation were assessed by one skilled observer without knowledge of the diagnosis. Ten preoperative radiographs of patients with osteoarthritis (five hip, five knee) were included as controls. The radiographs were assorted randomly and assessed for the degree of erosive change, joint space narrowing, subchondral sclerosis, and osteophyte formation. Each feature was scored on a scale from 0 to +++ and a radiological diagnosis of rheumatoid arthritis or osteoarthritis attempted for hips and knees.

\section{Results}

PREVALENCE OF DIFFERENT TYPES OF CARTILAGE-PANNUS JUNCTION IN RHEUMATOID JOINTS

When the prevalence of the different types of cartilage-pannus junction was analysed for different joints a difference between large weightbearing joints (hips/knees) and smaller joints was identified (table 2). The invasive cartilage-pannus junction pattern occurred in $11 / 15(73 \%)$ metatarsophalangeal joints and was twice as common as in either hips $(p<0.01)$ or knees $(p<0.05)$. In contrast, the presence of a transitional fibroblastic zone was found predominantly in the large joints (hips $v$ meta-

Table 2 Prevalence of invasive (distinct) or transitional fibroblastic zone (TFZ indistinct) patterns found in sections taken from the cartilage-pannus junction (CPY) in different joints. Number (\%) of sections is shown

\begin{tabular}{|c|c|c|c|c|c|c|}
\hline Foint & $\begin{array}{l}\text { Number of } \\
\text { joints }\end{array}$ & $\begin{array}{l}\text { Number of } \\
\text { sections }\end{array}$ & $\begin{array}{l}\text { Invasive/distinct } \\
C P \mathcal{F}\end{array}$ & $\begin{array}{l}T F Z \text { /indistinct } \\
C P \mathcal{Y}\end{array}$ & $\begin{array}{l}\text { No pannus } \\
\text { found }\end{array}$ & $\begin{array}{l}\text { Invasive } \\
\mathrm{v} \text { TFZt }\end{array}$ \\
\hline $\begin{array}{l}\text { Knee* }^{*} \\
\text { Hip** } \\
\text { Metatarsophalangeal } \\
\text { Radial head }\end{array}$ & $\begin{array}{r}11 \\
7 \\
4 \\
1\end{array}$ & $\begin{array}{r}57 \\
48 \\
15 \\
4\end{array}$ & $\begin{array}{r}22(39) \\
19(40) \\
11(73) \\
3(75)\end{array}$ & $\begin{array}{r}29(51) \\
15(31) \\
1(7) \\
-\quad\end{array}$ & $\begin{array}{r}10(18) \\
16(33) \\
3(20) \\
1(25)\end{array}$ & $\begin{array}{l}\text { NS } \\
\text { NS } \\
\mathrm{p}<0.05 \\
-\end{array}$ \\
\hline $\begin{array}{l}\text { Knee } v \text { hip } \ddagger \\
\text { Knee } v \text { MTP } \neq \Phi \\
\text { Hip } v \text { MTP } \ddagger\end{array}$ & & & $\begin{array}{l}\text { NS } \\
p<0.05 \\
p<0.01\end{array}$ & $\begin{array}{l}\text { NS } \\
p<0.01 \\
p<0.05\end{array}$ & $\begin{array}{l}\text { NS } \\
\text { NS } \\
\text { NS }\end{array}$ & \\
\hline
\end{tabular}

* In six sections (four knee, two hip) both types of cartilage-pannus junction were present.

$+W$ ilcoxon matched pairs signed rank test.

$¥$ Mann-Whitney U test.

SMTP = metatarsophalangeal joint. 
tarsophalangeal joints, $\mathrm{p}<0.05$; knees $v$ metatarsophalangeal joints $p<0.01$ ), being present in only one of 15 sections in the small joint group. The prevalence of both types of cartilagepannus junction was similar in hip joints. In knees a fibroblastic zone was found more often than invasive junctions, but this difference was not statistically significant.

Examples of both types of junction were found in different sections within eight joints (four knee, three hip, one metatarsophalangeal joint). In addition, in six sections, (four knee, two hip) obtained from these joints both types of junction were present within the section, showing that one pattern can merge with the other. These sections tended to be larger and extended to a maximum of $1 \mathrm{~cm}$ along the cartilage-pannus junction. In the other 15 joints, however, either a fibroblastic or invasive pannus was seen exclusively in multiple sections from each joint.

Some sections were present without any identifiable surface pannus tissue overlying the cartilage. In these sections the junctional area consisted of either an abrupt change from synovium to cartilage without any tissue overlying the cartilage or, more commonly, a small wedge shaped lip of tissue overlying the cartilage surface, consisting entirely of synovial-type fibroblasts. This latter appearance, in which there is a distinct junction with the cartilage, is similar to that found in normal human joints and differs from the pathological fibroblastic zone both in morphology and immunohistochemical characteristics. ${ }^{23}$

CONDITION OF THE ARTICULAR CARTILAGE

The cartilage in which an invasive cartilagepannus junction was present generally had

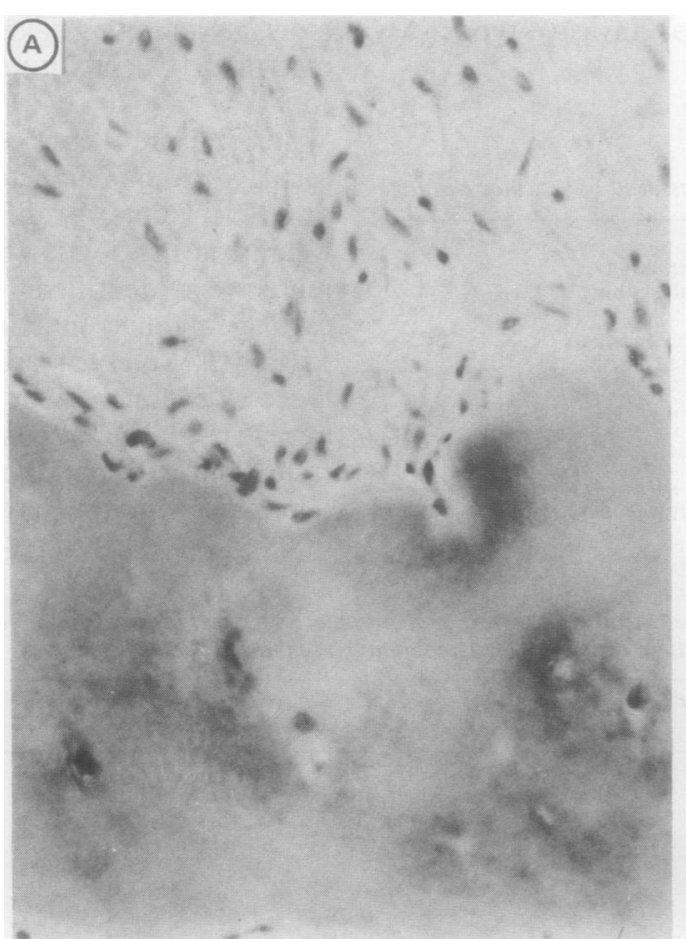

extensive depletion of proteoglycans and was often in very poor condition, with a paucity of chondrocytes, many empty lacunae, and nuclear debris (fig 2A). The depletion of proteoglycan staining was most prominent in the more superficial zones of cartilage adjacent to pannus, but in other sections extended to deeper zones with only some residual pericellular staining surrounding intact chondrocytes. In contrast, cartilage associated with a transitional fibroblastic zone showed stronger and more uniform safranin $\mathrm{O}$ staining for proteoglycan and contained chondrocytes that seemed in good condition with intact nuclear membranes and lacunae (fig 2B). In these sections the chondrocytes were numerous and occasional small clusters were seen.

The semiquantitative evaluation of proteoglycan depletion and chondrocyte necrosis confirmed that cartilage degradation was greater in invasive (distinct) cartilage-pannus junctions than in those with a transitional fibroblastic zone (indistinct) (fig 3). This relation reached significance for both hips $(p=0.01)$ and knees $(p=0.0005)$. Analysis was not possible for metatarsophalangeal joints as only one section had an indistinct cartilage-pannus junction. There was, not surprisingly, a significant correlation between proteoglycan depletion and the degree of chondrocyte necrosis in both types of junction, reflecting diminished proteoglycan production in degenerating chondrocytes.

\section{RELATION BETWEEN HISTOLOGICAL AND RADIOLOGICAL FINDINGS}

The correct diagnosis of rheumatoid arthritis ( $v$ osteoarthritis) was made without knowledge of the diagnosis from the preoperative radiographs in all rheumatoid hip joints, but in only $7 / 10$

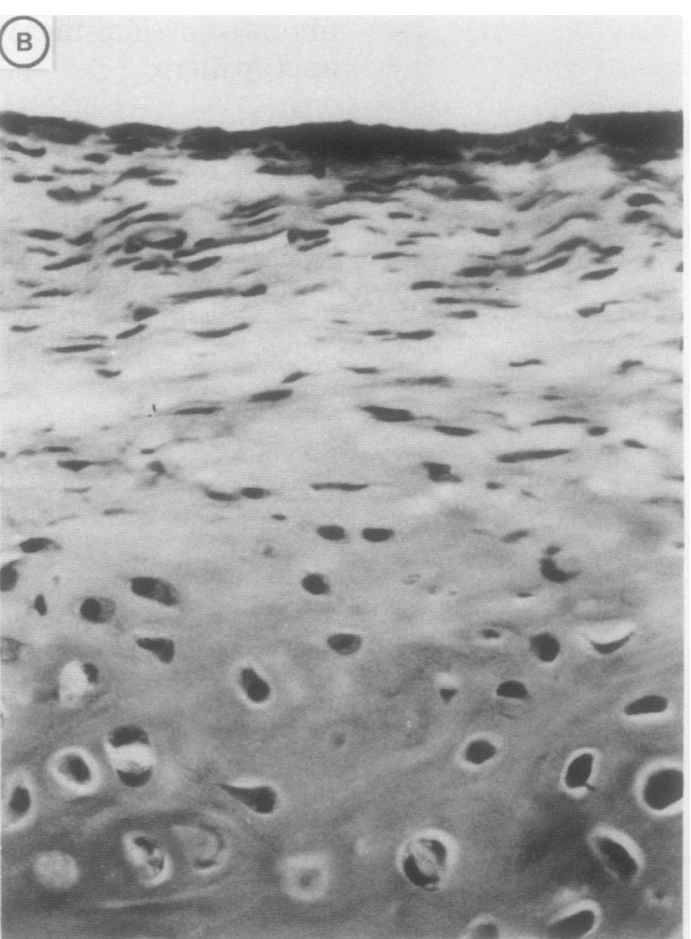

Figure 2 (A) A distinct ('invasive') cartilage-pannus junction, in which the underlying cartilage is depleted of proteoglycans, contains few intact chondrocytes and several empty lacunae. (Safranin $O).(B) A n$ indistinct ('fibroblastic') cartilage-pannus junction in which the underlying cartilage stains intensely for proteoglycans and contains numerous chondrocytes. (Safranin 


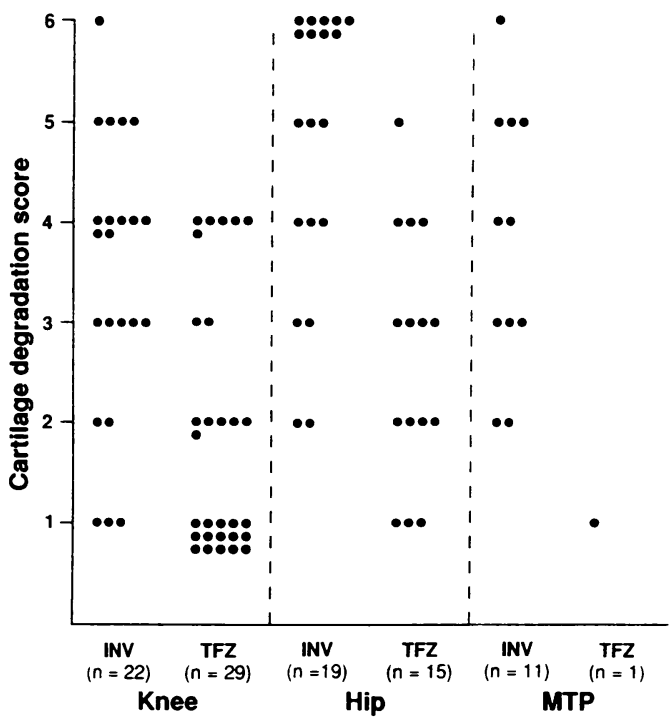

Figure 3 Comparison of the degree of cartilage degradation (6= maximum degradation - see table l) in 'invasive' (INV) and 'fibroblastic' (TFZ) types of cartilage-pannus junction for each section with pannus. The degree of cartilage degradation is more marked when a distinct ('invasive') cartilage-pannus junction is present in knee $\left(p=0.0005^{*}\right)$, hip $\left(p=0.01^{*}\right)$, and metatarsophalangeal joints (MTP). ${ }^{*}$ Mann-Whitney $U$ test.

(70\%) rheumatoid knees. In addition, osteophytes were observed in $8 / 10(80 \%)$ rheumatoid knees, but in only $2 / 7$ (29\%) hips included in this study. Radiological erosions were reported in all but one of the knee and hip joints, but differentiation from subchondral cystic changes in these joints was sometimes difficult. In contrast, the 'blinded' observer made the correct diagnosis from all five osteoarthritic knee and $3 / 5(60 \%)$ osteoarthritic hip radiographs included in this analysis.

The presence of radiological osteophytes was invariably associated with the presence of a transitional fibroblastic zone on histological examination in rheumatoid knee and hip joints. Conversely, however, a fibroblastic zone was present in sections from three rheumatoid hip joints that scored zero for osteophytosis. This differed from knees in that a fibroblastic zone could not be found in any histological section examined from the two rheumatoid knees without radiological osteophytes. This discrepancy may reflect differences in visualising osteophytes in hips and knees by routine radiology.

Radiologically the metatarsophalangeal joints showed a consistent pattern, all four sets scoring maximally- +++- for erosions, and zero for both osteophytosis and sclerosis. Joint space narrowing was recorded as strongly positive++ to +++ -in all joints. As all the metatarsophalangeal joints were characterised histologically by invasive pannus this suggests a correlation between this type of pannus and radiological erosion. A similar correlation with erosion was not as evident in knee and hip joints, but this might also reflect difficulties in detecting erosions in large joints by conventional radiology.

Discussion

The conventional view that destruction of rheumatoid joints is due to the direct invasion of cartilage and bone by pannus is based largely on morphological studies of the cartilage-pannus junction. ${ }^{1-5}$ The sequence of events in the formation of pannus tissue has been postulated from such studies. The presence of a fibroblastic layer between vascular pannus and cartilage (which we have called the transitional fibroblastic zone) has usually been thought of as a late feature of rheumatoid pannus. ${ }^{4524}$ The presence of such 'fibroblastic pannus' has resulted in much controversy as to the relative contribution of cartilage or synovium in the formation of pannus.

We have shown, using monoclonal antibodies, that the transitional fibroblastic zone comprises cells and matrix that contain components specific for cartilage, such as keratan sulphate, chondroitin sulphate, and type II collagen, and not antigens associated with synovial or capsular tissues. ${ }^{2021}$ In addition, the indistinct junction that this tissue forms as it merges with the underlying articular cartilage suggests that this zone is derived from metaplastic change of the articular cartilage. Actual synthesis of proteoglycans specific for cartilage by cells within the fibroblastic zone is also supported by immunolocalisation of keratan sulphate to the endoplasmic reticulum of these cells at electron microscopy. ${ }^{25}$ An alternative explanation is that this tissue is derived from 'immature' mesenchymal cells from adjacent tissues which have developed the ability to synthesise cartilage components, though this tissue is apparently different from the destructive 'immature' cells described by Fassbender. ${ }^{5}$ Recent work suggests that there may be cells able to synthesise these components within periosteal tissue adjacent to cartilage at the junction with synovium in normal human joints. ${ }^{23}$

Although the cartilage in rheumatoid arthritis has been previously studied, ${ }^{26}$ the relation with changes in the overlying pannus has rarely been noted. ${ }^{7}$ In this study we showed that when a transitional fibroblastic zone is present the underlying cartilage contains many intact chondrocytes and often stains intensely for proteoglycans with metachromatic stains such as safranin $O$. The presence of cells actively synthesising keratan sulphate within the fibroblastic zone, and the association of this zone with an intact underlying articular cartilage rich in proteoglycans, suggests that this pattern of tissue reaction may represent an attempt at regeneration of a proteoglycan-rich matrix. Similar morphological changes can be seen in joints from patients with primary-osteoarthritis $^{20} 27$ and in experimental models of osteoarthritis. $^{28}$

The evolution of the transitional fibroblastic zone is unclear but, possibly, it represents altered articular cartilage secondary to changes induced by cytokines in chondrocytes and their matrix. This is supported by similar cellular changes seen in vitro in cartilage. ${ }^{29} 30$ Unlike cartilage adjacent to the fibroblastic zone present in our study, however, the matrix of cartilage under the influence of cytokines is depleted of proteoglycans. ${ }^{31}$

The cartilage associated with invasive pannus 
has not only been depleted of proteoglycans but also contains chondrocytes which seem degenerate. This type of cartilage-pannus junction must therefore represent a late stage in the destructive phase of the disease. By definition, early stages in pannus formation are unlikely to be found in tissue obtained from operative specimens, and this is true for all previous human studies of the cartilage-pannus junction. The finding of collagenase and other proteolytic enzymes in such tissues, however, emphasises the chronicity of the disease in rheumatoid arthritis. ${ }^{32}$

Few previous studies have paid attention to which joint has been studied. Some changes, such as underpinning of cartilage by inflammatory cells, have been noted as a common feature of small joints. ${ }^{7}$ Fibrous pannus has been said to occur in $70 \%$ of cartilage-pannus junctions in rheumatoid arthritis. ${ }^{33}$ Previous authors who emphasised the contribution of cartilage to the formation of pannus were usually studying knees ${ }^{8}$ or hips. ${ }^{34}$ Fibroblastic pannus has, however, also been found in small joints. ${ }^{7}$ Because the sampling techniques selected areas containing both cartilage and pannus it was not possible to be certain that both types of cartilage-pannus junction were not present in every joint in our study. We suggest, however, that fibroblastic pannus is common in large joints but rare in small joints. This predilection for large lower limb joints may suggest that this tissue reaction results from external demands, such as weight bearing. This hypothesis is supported by a similar reaction shown in tendon fibroblasts subjected to compressional forces. These areas of tendon contain substantial amounts of high molecular weight glycosaminoglycans, including keratan sulphate, not present in regions subjected only to tensional forces. ${ }^{35} 36$ In addition, the presence of a proteoglycan-rich matrix in the cartilage adjacent to the transitional fibroblastic zone is consistent with the enhanced proteoglycan content and biosynthetic rates found in regions of more highly loaded articular cartilage. ${ }^{37}$

It is important to note that the histology of the normal human synovial-cartilage junction differs between large and small joints, and this in itself is likely to result in variation in the disease of different joints. A fibrous overlay of tissue onto the cartilage surface is found at the cartilage margin of normal joints. ${ }^{38}$ It is a prominent feature in the knee but, although present, is less prominent in small joints. This normal fibrous overlay differs both histologically and immunohistochemically from the pathological fibroblastic zone. ${ }^{23}$ It is contiguous with the area between cartilage and synovium, which in normal joints is sometimes referred to as the marginal transitional zone. ${ }^{39}$ This term should not be confused with the transitional fibroblastic zone in diseased joints.

Radiologically, rheumatoid erosions are seen without difficulty in small joints such as metatarsophalangeal joints, but are rarely seen in large joints, in which joint space narrowing is the most constant finding. This may partly be owing to technical problems in visualising small erosions in large joints. Our results emphasise both the clinical and histopathological differences between large and small joints in rheumatoid arthritis. Thus a correlation is suggested between radiological marginal erosion and the predominance of 'invasive pannus' in small joints, and the radiological change of progressive generalised loss of cartilage with 'fibroblastic pannus' in large weightbearing joints.

We thank Dr J Mclvor, Charing Cross Hospital, for the radiological assessment, Dr K McCrae, Charing Cross Hospital, for statistical advice, and Mrs K L Camplejohn for assistance in scoring of sections. We thank the Arthritis and Rheumatism Council (ARC) for their generous financial support. SAA was supported by an ARC junior fellowship and KDM by a grant
superial (ARC) for their generous financial support. SAA was supported by an ARC junior fellowship and KDM by a grant
from the National Health and Medical Research Council of from the

1 Ball J. Pathological aspects of rheumatoid arthritis. In Hijmans W, Paul W D, Herschel H, eds. Early synovectom in rheumatoid arthritis. Amsterdam: Excerpta Medica, 1969: 23-7.

2 Gardner D L. Pathology of rheumatoid arthritis. In: Scott J T, ed. Copeman's textbook of the rheumatic diseases. 6th ed. Edinburgh: Churchill Livingstone, 1986: 604-52.

3 Kobayashi I, Ziff M. Electron microscopic studies of the cartilage-pannus junction in rheumatoid arthritis. Arthritis cartilage-pannus junction in

4 Shiozawa S, Shiozawa K, Fujita T. Morphologic observations in the early phase of the cartilage-pannus junction. Arthritis Rheum 1983; 26: 472-8.

5 Fassbender H G. Histomorphological basis of articular cartilage destruction in rheumatoid arthritis. Collagens and Related Research 1983; 3: 141-51.

6 Muirden K D. Microscopic studies of the synovial-cartilage junction in rheumatoid arthritis. Eur $\mathcal{F}$ Rheumatol Inflamm 1982; 5: 30-8.

7 Barrie $\mathbf{H ~ J}$. Histological changes in rheumatoid disease of the metacarpal and metatarsal heads as seen in surgical metacarpal 7 and metatarsal heads as

8 Mills K. Pathology of the knee joint in rheumatoid arthritis. 7 Bone foint Surg [Br] 1970; 52: 746-56.

Bromley M, Woolley D E. Histopathology of the rheumatoid lesion. Arthritis Rheum 1984; 27: 857-63.

10 Takasugi S, Inoue H. Pannus tissue at the cartilage-synovium junction in rheumatoid arthritis. Acta Med Okayama 1988 42: 83-95.

11 Mitrovic $D$. The mechanism of cartilage destruction in rheumatoid arthritis. Arthritis Rheum 1985; 28: 1192-3.

12 Fassbender H G. The mechanism of cartilage destruction in rheumatoid arthritis: reply to

13 Shiozawa $S$. The mechanism of cartilage destruction in reumatoid arthritis: reply to letter by Dr Mitrovic. ${ }^{11}$ rheumatoid arthritis: reply to letritis Rhewm 1985; 28: 1193-5.

14 Cooke T D V. Rheumatoid arthritis pannus: true or false? Arthritis Rheum 1985; 28: 1195-7.

15 Woolley D E, Bromley M, Evanson J M. Rheumatoid pannus: true or false?: reply to letter by Dr Cooke. Arthritis Rheum 1985; 28: 1197-8.

16 Klareskog L, Johnell O, Hulth A. Expression of HLA-DR and HLA-DQ antigens on cells within the cartilage-pannus junction in rheumatoid arthritis. Rheumatol Int 1984; 4 (suppl): 11-15.

17 Klareskog L, Johnell $O$. Induced expression of class II transplantation antigens in the cartilage-pannus junction in RA: chronic synovitis as a model system for aberrant RA: chronic synovitis as a model system for aberrant II): 141-9.

18 Salisbury A K, Duke O, Poulter L W. Macrophage-like cells of the pannus area in rheumatoid arthritic joints. Scand $\mathcal{F}$ Rheumatol 1987; 16: 263-72.

19 Allard S A, Muirden K D, Maini R N. Differentia expression of MHC class II antigens and macrophage subpopulations in rheumatoid pannus. $\operatorname{Br} \mathcal{F}$ Rheumato 1987; 26: 124.

20 Allard S A, Muirden K D, Camplejohn K L, Maini R N Chondrocyte-derived cells and matrix at the rheumatoid cartilage-pannus junction identified with monoclonal antibodies. Rhewumatol Int 1987; 7: 153-9.

21 Allard S A, Maini R N, Muirden K D. Cells and matrix expressing cartilage components in fibroblastic tissue in rheumatoid pannus. Scand $\mathcal{J}$ Rheumatol 1988; suppl 76: rheuma.

22 Rosenberg L. Chemical basis for the histological use of safranin $\mathrm{O}$ in the study of articular cartilage. $\mathcal{F}$ Bome $\mathcal{F}$ oint Surg $[A m]$ 1971; 53: 69-82

23 Allard S A, Bayliss M, Maini R N. The synovial-cartilage junction of the normal human knee. Implications for joint destruction and repair. Arthritis Rheum 1990; 33: 1170-9.

24 Ziff $M$. Factors involved in cartilage injury. $\mathcal{J}$ Rheumato 1983; 11 (suppl): 13-25.

25 Muirden K D, Allard S A, Rogers K, Maini R N. Immunoelectron microscopy of chondrocyte-derived cells in the rheumatoid cartilage-pannus junction. Rheumatol Int 1988, 8: $231-4$.

26 Mitchell N S, Shepherd N. Changes in proteoglycan and collagen in cartilage in rheumatoid arthritis. $\mathcal{J}$ Bone foin Surg [Am] 1978; 60: 346-54. 
27 Collins D H. The pathology of articular and spinal diseases. London: Arnold, 1949: 88-97.

28 Moskovitz R W, Goldberg V M. Studies of osteophyte pathogenesis in experimentally induced osteoarthritis. F Revomatol 1987; 14: 311-20.

29 Fell H B, Jubb R W. The effect of synovial tissue on the breakdown of articular cartilage in organ culture. Arthritis Rheum 1977; 20: 1359-71.

30 Lavietes B B, Diamond H S, Carsons S E. Possible contribution of cartilage to fibrous pannus. Arthritis Rheum 1987; 30: 119-20.

31 Dingle J T. The effect of synovial catabolin on cartilage synthetic activity. Connect Tissue Res 1984; 12: 277-86.

32 Woolley D E, Crossley M J, Evanson J M. Collagenase at site of cartilage erosion in the rheumatoid joint. Arthritis $R$ heum 1977; 20: 1231-9.

33 Fassbender H G, Simmling-Annefeld M. The potential aggressiveness of synovial tissue in rheumatoid arthritis. F Pathol 1983; 139: 399-406.

34 Tateishi $H$. Ultrastructure of the synovio-cartilage junction in rheumatoid arthritis. Kobe f Med Sci 1973; 19: 51-66.

35 Vogel K G, Koob T J. Structural specialization in tendons under compression. Int Rev Cytol 1989; 115: 267-93.

36 Vogel K G, Thonar E J-M A. Keratan sulphate is a component of proteoglycans in the compressed region of component of proteoglycans in the compressed region of

37 Kiviranta I, Jurvelin J, Tammi M, Säămänen A-M, Helminen Kiviranta I, Jurvelin J, Tammi M, Säämänen A-M, Helminen
H J. Weight bearing controls glycosaminoglycan concentration and articular cartilage thickness in the knee joints of young beagle dogs. Arthritis Rhewn 1987; 30: 801-9.

$38 \mathrm{Key} \mathrm{J}$ A. The synovial membrane of joints and bursae. In: Cowdry E V, ed. Special cytology. New York: Hoeber, 1932: 1055-76.

39 Thompson A M, Stockwell R A. An ultrastructural study of the marginal transitional zone in the rabbit knee joint. f Anat 1983; 136: 701-13. 